\title{
A QUALIFICAÇÃo DE PERIÓdICOS NA ÁREA DE LETRAS E LINGUÍSTICA: QUESTÕES PARA REFLEXÃO
}

Ida Alves ${ }^{1}$

RESUMO: Trata-se de breve apresentação sobre a avaliação de periódicos acadêmicos e a aplicação de métricas na Área de Letras e Linguística. Avaliações quantitativa e qualitativa, problemas e possibilidades. Ensaio de avaliação de periódicos a partir de citação num conjunto restrito de trabalhos finais de pós-graduação (nível doutorado - Estudos Literários) nota 6 e 7: leitura crítica dos resultados obtidos.

PALAVRAS-CHAVE: Avaliação de Periódicos. Avaliação Quantitativa. Avaliação Qualitativa. Área de letras e Linguística. Métricas.

ABSTRACT: This is a brief presentation on the evaluation of academic journals and application of metrics in the Area of Letters and Linguistics. Quantitative and qualitative evaluations, problems and possibilities. Assessment test of periodic based on quotation on a limited set of graduate final works (doctoral level - Literary Studies) grade 6 and 7: critical reading of the results.

KEYWORDS: Evaluation of Journals. Quantitative Assessment. Qualitative Assessment. Area of Letters and Linguistics. Metrics.

$1 \mathrm{UFF} / \mathrm{CAPES}$. Por ocasião da redação deste texto, a autora exercia a função de Coordenadora Adjunta da Área Letras e Linguística, na CAPES. Sua apresentação oral ocorreu no XXX Encontro da ANPOLL, realizado de 6 a 8 de julho de 2015, na USP. 


\section{A QUALIFICAÇÃO DE PERIÓdICOS NA ÁREA DE LETRAS E LINGUÍSTICA: QUESTÕES PARA REFLEXÃO}

Não é só no Brasil que as práticas de avaliação da produção acadêmica são aplicadas e discutidas, com ênfase positiva ou negativa. Em todos os países envolvidos com esse tipo de produção, nas diversas áreas de conhecimento, buscam-se parâmetros objetivos para dar conta da diversidade de práticas de investigação e circulação de seus resultados. $\mathrm{O}$ "Manifesto de Leiden" 2 sobre métricas de pesquisa, publicado na revista Nature em 22 de abril de 2015, é, por exemplo, um documento bastante interessante para pensar criticamente o ato avaliativo. Seus autores, Diana Hicks (professora na School of Public Policy do Georgia Institute of Technology, EUA) e Paul Wouters (diretor do CWTS na Leiden University, Holanda), com mais três pesquisadores (Espanha, Reino Unido e França), discutem nesse texto dez princípios para avaliar a produção de pesquisa. Também entre nós esse estudo recebeu atenção e mesmo no âmbito da CAPES foi divulgado e discutido no CTC - Conselho Técnico-Científico. Notese que tal estudo foi traduzido em mais de dez línguas, incluindo português, espanhol, persa, russo, chinês, basco, coreano, italiano, francês. Os dez princípios elencados - e citamos da tradução brasileira realizada por Sibele Fausto, do Sistema Integrado de Bibliotecas da Universidade de São Paulo (DT-SIBiUSP) - são os seguintes: 1. A avaliação quantitativa deve dar suporte à avaliação qualitativa especializada; 2. Medir o desempenho de acordo com a missão da instituição, do grupo ou do pesquisador; 3. Proteger a excelência da pesquisa localmente relevante; 4. Manter a coleta de dados e os processos analíticos abertos, transparentes e simples; 5. Permitir que os avaliados verifiquem os dados e as análises; 6 .

2 Para leitura de tradução desse texto, acessar http://www.leidenmanifesto.org/uploads/4/1/6/0/41603901/leidenmanifesto-portuguese-br-final.pdf . Para leitura do texto em inglês, ver http://www.leidenmanifesto.org/ 
Considerar as diferenças entre áreas nas práticas de publicação e citação; 7. Basear a avaliação de pesquisadores individuais no juízo qualitativo da sua carreira; 8. Evitar solidez mal colocada e falsa precisão; 9. Reconhecer os efeitos sistêmicos da avaliação e dos indicadores; 10. Examinar e atualizar os indicadores regularmente.

O documento propõe oferecer "síntese das melhores práticas de avaliação da pesquisa baseada em métricas, para que os pesquisadores possam confiar em seus avaliadores, e para que os avaliadores possam confiar em seus indicadores." No entanto, não são esse "Manifesto" e suas implicações o objeto desta nossa reflexão. Nossa atenção dirige-se à produção veiculada em periódicos, mais de 1.600 (somando nacionais e estrangeiros, de Letras e de outras Áreas), citados por todos os professores credenciados em nossos Programas de Pós-Graduação (mais de 140) em suas rotinas de recolha de dados de produção trienal e, agora, quadrienal.

Interessa-nos propor um olhar mais atento à importância dos periódicos para a Área de Letras e Linguística. Acreditamos que nenhum de nós seja descrente em relação à contribuição que um periódico especializado, bem estruturado, possa ter na imprescindível tarefa de divulgação ampla de pesquisas, de resultados e de objetos de trabalho. O periódico é veículo excelente para circulação dinâmica do pensamento e debate atualizado de perspectivas, abre janelas, convida ao diálogo, aponta caminhos e reúne vozes diversas em trabalho de pensamento e análise. Nesse sentido, qual é o periódico que pode realizar de maneira plena tal tarefa? Pensemos algumas características:

1- que seja relacionado diretamente à nossa grande Área de Letras e Linguística, com suas subáreas, pois atinge os leitores críticos que desejamos ter para nossas investigações e resultados;

2- que esteja, em termos editoriais, sempre atualizado, pois o movimento de pesquisa não para. Nossos trabalhos demonstram um estado de investigação e devem ser divulgados em tempo ágil, se pretendemos interferir na reflexão de determinada área ou questão, até para receber o retorno crítico necessário para alteração de rumos.

3- que seja visível aos leitores, ou seja, com forte divulgação nacional e mesmo internacional, pois queremos que nossas ideias ultrapassem os limites de nossa mesa de trabalho e de nossa universidade. Se impresso, com rede e controle de distribuição que realmente funcionem para estar presente em livrarias e bibliotecas em todas as regiões do país e, se possível, em centros de excelência internacionais da área de conhecimento; se eletrônico, num site muito bem elaborado, indexado nacional e internacionalmente, com acesso livre, downloads gratuitos dos artigos e com todas as condições editoriais necessárias para catalogação bibliográfica, circulação e registro de produção.

4- que seja, em sua concepção, em sua política e em sua execução editorial, um espaço de ampla discussão, de divulgação rigorosa de conhecimento, isto é, um veículo exógeno, com efetiva avaliação de pares e exigente controle de qualidade da publicação em todos os seus aspectos, reconhecido como espaço de relevância para a comunidade científica.

Para cada item anteriormente apontado, muitos aspectos divergentes podem ser considerados, ainda mais se pensamos que estamos falando disso em contexto brasileiro, em sua extensão, diversidade e dissimetrias. Não é fácil atingir todos esses parâmetros ou mantêlos em alto patamar na realidade universitária a que pertencemos, especialmente considerando, em geral, a falta de estrutura administrativa para manutenção de periódicos acadêmicos em nossas universidades estaduais e federais. 
Então, como tratar desse tema frente à necessidade de avaliação dos Programas de Pós-Graduação credenciados pela CAPES? Não é o periódico um meio importante para a circulação de estudos, de pesquisas em andamento ou em finalização realizadas nesses mesmos Programas? Se assim é, torna-se inevitável que tenhamos alguns indicadores qualitativos para diferenciar os periódicos citados em nossos Lattes em termos de relevância e mesmo eficiência comunicativa. Daí a existência para todas as quarenta e oito Áreas, no âmbito da CAPES, de documentos específicos sobre avaliação de periódicos, com a descrição de um conjunto de indicadores de avaliação. Naturalmente, em termos de análise avaliativa, é necessário que se considere a relação entre dados quantitativos e aspectos qualitativos e que tais aspectos sejam regularmente discutidos pela comunidade interessada para sua constante depuração e justa aplicação. É compreensível que o pesquisador, ao ser avaliado por critérios gerais, homogêneos, não se sinta plenamente satisfeito, já que há muitas variantes, mas também não é possível avaliar de maneira particular, o que poderia provocar muitos desequilíbrios e mesmo avaliações viciosas. A existência e a aplicação de critérios universais, evitando o julgamento por idiossincrasias, salvaguardam o ato avaliativo e impedem que injustiças ou distorções sejam cometidas.

Nossa coordenação de Área $^{3}$ tem desenvolvido um trabalho o mais transparente e partilhado possível de acompanhamento e avaliação dos seus Programas, em todos os seus aspectos. Também vem autoquestionando, em seminários sobre nossos campos específicos de conhecimento, não só o perfil de nossa Área e subáreas, nossas balizas de trabalho científico, como também todos os critérios necessários para que o trabalho de avaliação se efetive da forma realmente equilibrada. O processo de avaliação envolve docentes e discentes, o olhar crítico, a leitura atenta, o pensamento questionador de pares que devem se debruçar sobre aspectos diversos de atuação de colegas que integram, afinal de contas, os Programas de PósGraduação. Essa avaliação é um trabalho humano e, por isso, sempre passível de transformação em busca de seu maior aperfeiçoamento.

Foi com essas ideias em mente que fizemos no primeiro semestre de 2015 um exercício diferente, e não oficial, de avaliação de periódicos, para testar uma hipótese de trabalho: se desejamos que os periódicos da Área sejam valorados especialmente por sua contribuição qualitativa, é preciso verificar onde ou como eles estão sendo acionados, ou seja, pesquisados, lidos, questionados. Ou seja: os nossos periódicos de Área são fontes bibliográficas constantes em nossos trabalhos de conclusão de cursos de Pós-Graduação (Mestrado e Doutorado)? Nossa produção de artigos críticos, analíticos, teóricos está, qualitativamente, impactando nossa Área, na medida em que interfere na formação de novos pesquisadores ou contribui efetivamente para os rumos de novas investigações? Os nossos artigos são realmente lidos, questionados, circulam no país e fora dele, no âmbito de nossa área de atuação, pelo menos?

Para responder a isso e demonstrar essas "qualidades", qual deveria ser nossa metodologia de avaliação? Uma possibilidade rigorosa seria haver um banco de dados destacando, a cada dissertação e tese (produtos finais dos cursos de Pós-Graduação) tornada pública nos bancos de dissertações e teses de sua universidade, os artigos em periódicos consultados, demonstrando assim as pesquisas, estudos que realmente circulam entre diferentes leitores da Área e interferem, com suas hipóteses e conclusões, nas pesquisas alheias, o que permitiria o cálculo de um fator de impacto que outras Áreas já utilizam a partir de ferramentas digitais de controle geral de citações. Hoje, a CAPES avalia, a cada ano, todos

3 Referimos-nos à gestão de Coordenação de Área Letras e Linguística no período de 2014-2016. Coordenador: Prof. Dr. Dermeval da Hora (UFPB); Coordenadora Adjunta: Profa. Ida Alves (UFF); Coordenadora para Mestrados Profissionais: Profa. Dra. Marcia Marques de Moraes (PUC-Minas). A partir de abril de 2016, assumiu a Coordenação Adjunta o Prof. Dr. Silvio Renato Jorge (UFF).

Ida Alves; A qualificação de periódicos na area de letras e linguística: questões para reflexão 
os periódicos que são citados pelos docentes em seus LATTES, ou seja, se publicamos na revista $X$, tal revista terá que ser avaliada. Mas, se não fosse assim? Se a CAPES avaliasse somente as que são citadas em dissertações e teses, como lugares de leitura e problematização? Claro que isso não é possível no sistema atual, pois demandaria outro tipo de registro continuado e mais extensa observação de dados. No entanto, resolvemos testar, como experiência apenas, essa hipótese de verificação avaliativa por amostragem para verificar que resultados poderíamos atingir.

Em decorrência, fizemos, na Área de Literatura, tomada aqui como um campo exploratório mais próximo, um levantamento crítico das referências bibliográficas / bibliografias de 147 teses de Doutorado de dois Programas de Pós-Graduação nota 7 e de três de nota 6, atuantes em duas regiões brasileiras, com acesso integral em Bancos de Teses Universitários, nos anos de 2013 e 2014. O que se pôde constatar, com a margem de falha previsível nesse tipo de exercício parcial, foi o que se segue:

1- Nesse conjunto de 147 teses sobre literatura brasileira, literatura comparada, teoria e crítica literária foram referenciados um total de 453 artigos (considerando nesse número bruto que há a repetição de um determinando número de títulos de periódicos), o que indica uma média de 3,08 artigos (veiculados em periódicos nacionais e estrangeiros) citados por tese. Citam-se muitos periódicos estrangeiros quando se trata de teoria e crítica literária; citam-se dominantemente os nacionais para análises específicas de autores brasileiros e em situação de literatura comparada. No conjunto dos 147 trabalhos examinados, cerca de 300 periódicos (muitos são estrangeiros) são citados, pelo menos com uma ocorrência.

2- Há um número restrito de periódicos nacionais e internacionais que são recorrentemente citados, em todos os Programas examinados, de acordo com área da pesquisa. Essa recorrência demonstraria que tais periódicos seriam então os mais relevantes?

3- Há uma prática visível de citação de artigos publicados em periódicos locais (isto é, do próprio Programa ou de grupos / núcleos da própria universidade), sem expansão para outros locais de produção reflexiva, ou seja, há uma prática visível de citação de artigos publicados em periódicos que pertencem à região geográfica do Programa de Pós-Graduação. É frequente, então, que uma tese $\mathrm{X}$ produzida em determinado Estado cite apenas periódicos de universidades do mesmo Estado e/ou de Estado diferente, mas pertencente à mesma região. A divulgação da produção nacional parece não estar ainda bem partilhada, conhecida, ainda mais se considerarmos que muitos periódicos, embora tenham portais on line, não facilitam o acesso direto aos PDFs, à série histórica do material impresso. Assim, de novo, só importa um determinado conjunto de periódicos? Somente um quantitativo limitado de autores que publicam nesse conjunto de periódicos é que produz conhecimento relevante para o desenvolvimento da Área? Seriam esses periódicos os que têm mais qualidades por estarem presentes constantemente como referências bibliográficas?

4- A quantidade de periódicos diferentes citados em cada tese, em geral, é muito pequena, variando de nenhum periódico a cinco. A produção de conhecimento que nos interessa em nossa Área está nos livros e não nos periódicos? Os periódicos não estão apresentando artigos impactantes e inovadores para nossos próprios percursos de pesquisa?

5- Em relação ao número de 453 artigos citados, considerando mais uma vez que diferentes artigos podem estar num mesmo periódico, a partir de uma perspectiva de análise dos dados cada vez mais seletiva, poderíamos demonstrar que somente 10 periódicos nacionais são constantemente citados como lugar de leitura consultado e utilizado (já que 
referenciados) por esses doutorandos dos PPGs observados. Neste nosso exercício, foram indicados, em ordem de citações: 1-Aletria; 2- Novos Cadernos CEBRAPA; 3-Remate dos Males; 4- Ipotesi; 5- Cadernos de Literatura Brasileira (do Instituto Moreira Salles); 6Scripta (MG); 7- Revista Brasileira de Literatura Comparada (ABRALIC); 8- O Eixo e a Roda; 9- Raído (Grande Dourados); e 10- Álea. Observe-se que eles têm um traço em comum: serem periódicos avaliados como A1 e A2. Com menos citações, mas presentes com certa constância: 1- Revista de Letras (UNESP), 2-Boletim CESP, 3- Teresa, 4-Gragoatá, 5Matraga, 6-Signótica, 7-Revista Abril Nepa UFF, 8- Itinerários, 9- Revista Desassossego, 10- Revista Letras Hoje, 11- Revista Crioula, 12- Fragmentos (Florianópolis), 13-Topoi, 14Cadernos de Letras da UFF e 15-Cadernos de Tradução. São periódicos A1, A2 e B. Seriam esses 25 periódicos, para estudos literários, os mais presentes por terem as qualidades essenciais a um periódico que interessa mais em nossa Área? A avaliação A e B desses periódicos, no Qualis CAPES, estaria de acordo então com a condição de serem recorrentes nos estudos produzidos na Área?

6- Constatou-se também a recorrência mínima de citação de estudos oriundos de anais de evento, com exceção de anais de associações de atuação nacional como, por exemplo, ABRALIC, o que, de certa maneira, demonstra como esse tipo de publicação tem realmente circulação muito restrita (era comum a publicação em CDs) e pouca especificidade temática.

7- Constatou-se também a preferência de consulta de artigos acessíveis on line, indicando previsivelmente como o periódico impresso, mas não acessível na rede integralmente, tem menor atração de leitura, presente apenas local ou regionalmente, na dependência de sua distribuição.

Ora, se esse recorte que fizemos correspondesse à totalidade, teríamos que concluir que, dos 700 periódicos da Área de Letras e Linguística ou dos 1.600 periódicos (considerando os 900 de outras Áreas, em que também publicamos, já que especialmente na Área de estudos literários a interdisciplinaridade é constante), somente uma pequena porcentagem (cerca de 5\%) foi utilizada como fonte de leitura e de pesquisa, isto é, apenas um número mínimo de revistas (e seus artigos...) foi realmente de interesse para os novos mestres e doutores. Em síntese, grosso modo: da grande quantidade de periódicos que temos, da grande quantidade de periódicos em que publicamos, apenas uma porcentagem restrita foi consultada pelos doutorandos dos PPGs de excelência examinados. Então, os periódicos, para nossa Área, não importam tanto? Ou, refazendo a pergunta, os periódicos relevantes, qualificados, são apenas os que são citados e verificados por esses leitores críticos?

Esse tipo de avaliação dos periódicos, com preocupação dominantemente qualitativa a partir de sua utilização para o andamento de novas pesquisas, seria mais eficiente? Seria mais justa?

Seja como for, cabe-nos pensar, como pesquisadores, o que desejamos quando apostamos na criação de um periódico. Será que estamos editando uma revista apenas para nos submetermos à avaliação quantitativa que tanto criticamos? Não seria mais importante para nossa Área termos um conjunto numérico limitado de periódicos realmente de abrangência nacional e internacional que fizessem circular de forma determinante a pesquisa que estamos produzindo, seja de relevância local, nacional ou internacional? Será que gastamos tanto esforço na criação e manutenção de revistas apenas para satisfação de desejos locais e endógenos? Quais são as revistas que nós mesmos, docentes pesquisadores, consideramos fundamentais para acompanhar a produção reflexiva em nossa Área? Estaremos 
dando a esses veículos de conhecimento a importância que merecem em nosso trabalho de orientação, na formação de novos docentes e pesquisadores, ultrapassando espaços locais e regionais, interesses e vaidades pessoais?

Enfim, há muitas perguntas a fazer para compreender o quadro complexo de produção em nossa Área. O certo é que o periódico é uma fonte de reflexão e de debate importante para os Estudos Literários e os Estudos Linguísticos, como também ocorre em muitas outras Áreas frequentemente chamadas de "ciências duras". Discutir sua existência, sua produção e os critérios de avaliação necessários para sua qualificação consequente é também, no fundo, pensar como o conhecimento se move em nossa Área e como nós, autores de artigos científicos, agimos para que esse conhecimento publicado seja realmente partilhado e avaliado no Brasil e no mundo. 